\title{
Virtual Comfort Evaluation as a New Paradigm of Health and Safety In Industrial Engineering
}

\author{
Alessandro Naddeo* \\ Department Of Industrial Engineering, University of Salerno - Via Giovanni Paolo II, 132 - 84084 Fisciano (SA), Italy
}

Since the first appearance of hand-tools, artisans and engineers spent their efforts in order to make hand-work as comfortable as possible. In the second half of twentieth-century, industrialists' consciousness raising about ergonomics and safety criteria made the preventive evaluation of ergonomics/comfort working conditions a must of product/process design. Nowadays, designers and engineers knows that a comfortable and ergonomics work-place can sensibly improve the global performance of an operator and can also reduce the risk of muscle-skeletal diseases and the consequent absence periods and/or insurance issues; nevertheless this knowledge is not always easy to be applied because of its costs both in economics then in Time To Market (TTM) increase terms.

New VP (Virtual Prototyping) techniques and their development and diffusion in industrial environments make possible, since 1990, designing and redesigning of work-place in virtual environment; DHM (Digital Human Modelling) technique allow to virtually evaluate the interaction between humans and the main commands/hand tools of machine/workplace. Those devices, together with ergonomics and comfort evaluation models, may allow the preventive evaluation of Human Machine Interfaces (HMI) both in terms of comfort/ ergonomics while processing a product than in terms of comfort/ ergonomics while using the product.

\section{State of the Art of HMI Evaluation}

In HMI design several parameters have to be correctly evaluated in order to guarantee a good level of safety and well-being of users (humans) and to avoid health problems like muscular-skeletal diseases $[1,2]$. ISO Standards give us a good reference on Ergonomics and Comfort: ISO 11228 regulation deals with several parameters for evaluating Postural Ergonomics in manual loads' push/pull, in manual loads' lifting and carrying and in repetitive actions; those parameters can be synthesized in a "Postural Load Index" that represents the Ergonomics level of examined posture [3,4].

Nevertheless, in practical ergonomic evaluation, each user gives a different feedback about the perceived well-being for the same posture, also if all criteria of ISO Standards are satisfied. Bibliographic references suggest many different methods to make ergonomic evaluation; the most used and known ones are Rapid Upper Limb Assessment (RULA [5]), Rapid Entire Body Assessment (REBA [6]) and Loading of the Upper Body Assessment (LUBA [7]). All those methods go by measurement of anthropometric parameters.

In last ten years ergonomic evaluations seem to be not sufficient for assuring a good level of well-being and whole safety of workers and users, so that researchers concentrates their efforts on the study of comfort evaluation. When all ergonomic parameters are measured and when they can be considered in a safe range, we can start to study the comfort perception while using a product or while working in a workplace.

Making a simple search, it's possible to find more than 100.000 scientific papers dealing with comfort and discomfort; most of these speak about relationship between environmental factors (like temperature, humidity, applied forces etc.) that can affect the perceived comfort/discomfort [8]. Several papers follow the assumption that there is a relationship between self-reported discomfort and musculoskeletal injuries and that those injuries affect the perceived comfort $[9,10]$; however, the theories relating comfort to products and product design characteristics are rather underdeveloped [2]; the few papers explaining the concept of comfort are Helander and Zhang [11], De Looze et al.[12], Moes [1] and Kuijt-Evers et al. [13]. A literature overview allows us to identify five main topics about the relationship between subjective perception of comfort/discomfort feeling and product/ process/interaction/environment/users' factors:

1) Sensory input $[14,15]$.

2) Activities during the measurement that influence comfort $[16,17]$.

3) Different body regions $[18,19]$.

4) Effect of contour of the product for the comfort experience $[4,20,21]$.

5) Physical loading [10,22,23].

On these bases in [13] is given an interesting schematization of the mechanism of comfort/discomfort perception that comes from the following Moes' [1] model represented in Figure1.

In this model five phases in the process before discomfort is experienced are represented: (I) - interaction, (E) - effect in the internal body, (P) - perceived effects, (A) - appreciation of the effects and - discomfort (D). Moes (2005) also describes that this process is dependent on the person, the seat, the purpose and why the seat is used. Moes says that if a person uses a seat with a specific purpose, the interaction (I) arises. For example, this interaction can consist of the pressure distribution of the contact area between the subject and seat. An interaction results in internal body effects (E), such as tissue deformation or the compression of nerves and blood vessels. These effects can be perceived (P) and interpreted, for instance as pain. The next phase is the appreciation (A) of the perception. If these factors are not appreciated, it can lead to feelings of discomfort (D). This model has been modified by Vink and Hallbeck [2] in the following Figure 2.

The interaction (I) with an environment is caused by the contact (could also be a non-physical contact, like a signal in the study of De Korte et al. [14]) between the human and the product and its usage. This can result in internal human body effects $(\mathrm{H})$, such as tactile sensations, body posture change and muscle activation. The perceived effects $(\mathrm{P})$ are influenced by the human body effects, but also by expectations (E).

*Corresponding author: Department Of Industrial Engineering, University of Salerno - Via Giovanni Paolo II, 132 - 84084 Fisciano (SA), Italy, Phone: +39 089 964311, Fax: +39089964037, Mobile: +39 320 7406170, Email: anaddeo@unisa.it

Received August 21, 2013; Accepted August 23, 2013; Published August 28, 2013

Citation: Naddeo A (2013) Virtual Comfort Evaluation as a New Paradigm of Health and Safety In Industrial Engineering. Ind Eng Manage 2: e119. doi: 10.4172/21690316.1000e119

Copyright: $\odot 2013$ Naddeo A. This is an open-access article distributed under the terms of the Creative Commons Attribution License, which permits unrestricted use, distribution, and reproduction in any medium, provided the original author and source are credited. 


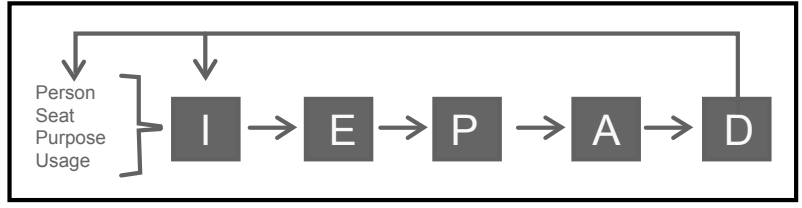

Figure 1: Moes model of discomfort perception.

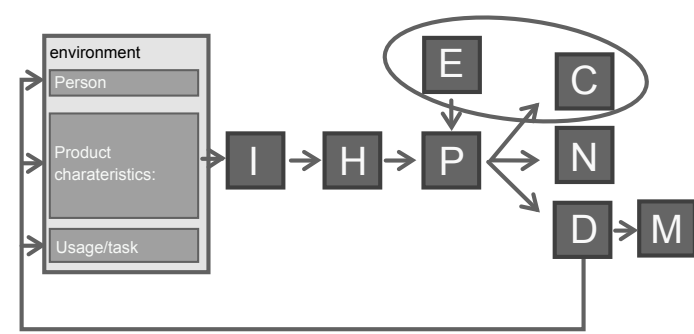

Figure 2: Vink-Hallbeck model of comfort/discomfort perception.

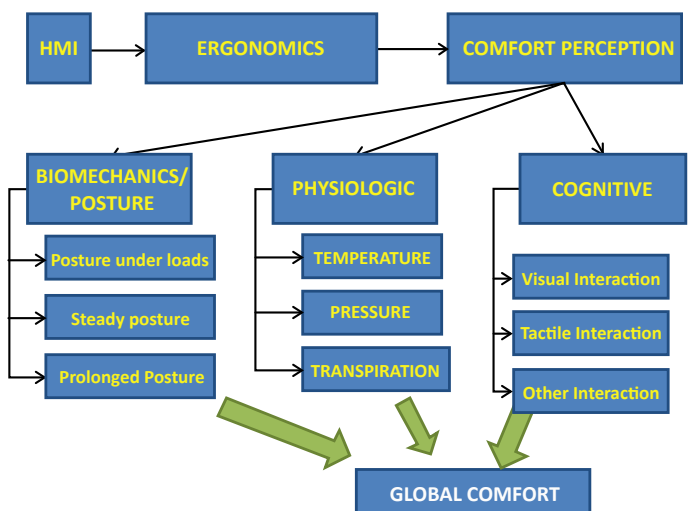

Figure 3: Simplified comfort perception scheme.

These are interpreted as comfortable (C) or you feel nothing $(\mathrm{N})$ or it can lead to feelings of discomfort (D). In this model the internal body effects and the perceived effects plays a fundamental role in the comfort/ discomfort perception/evaluation and the definition of Maximum Level of Comfort (MLC) positions in human postures seems to be one of the most important tasks in this kind of comfort evaluation model [3,24-26] especially if based on measurement of the angular Range of Motion (ROM) of each joint.

\section{A Simplified Comfort Model: Importance of Postural Comfort on Global Comfort Perception}

A simplified model that seems to work well with the Vink-Hallbeck one can be easily explained in the Figure n. 3 in which three main comfort aspects can be identified.

Efforts of researchers are now concentrated in developing a good Fusion Rule for information coming from objective/subjective measurements of three main components of comfort perception. The fourth one, environmental/social comfort, has not been taken into account because it is not strictly related to HMI studies and because it can be easily checked in experimental set-up.

The other great efforts are made in objectivising all measurements for virtual prototyping the whole perception in HMI. The most analyzed of three "kinds of comfort" is obviously the postural comfort because it seems to mainly affect the whole comfort and it is the most difficult to be measured without altering the comfort perception. Low-invasive and cheap methods for human-joints measurements (i.e. photogrammetry) and definition of comfort-functions having, as input, only joints' angles seem to be the new frontier of international studies.

Postural comfort level is very hard to detect and measure because it's affected by individual judgments that can be analyzed using quantitative/qualitative methods. Several approaches have been used by researchers in order to objectivise postural comfort performances but a lot of work has still to be done. Some recent works studies the effect of Rest Positions on perceived comfort of upper limbs [26], also developing a comfort-rate method based on posture analysis [27]. Another work by the same author deepens the relation between global comfort and postural comfort in controlled physiologic conditions [28].

\section{Conclusions}

In industrial work-place redesign and in new plant-layout and work place design a good approach in HMI evaluation in terms of ergonomics and comfort may improve workers' safety and comfort and, consequently, improve productivity and lower healthy problems (both in terms of lost of working-days than in terms of insurance costs). The best way to implement this kind of approach is to spread over the ergonomics/comfort knowledge in working environments and develop methods to evaluate ergonomics/comfort of HMI in the early phase of design/redesign of a work-place. The same approach can be used to improve ergonomics/comfort of products in order to improve quality and make products more attractive on market.

According with comfort-scheme in Figure 3, researchers have to create/improve methods for evaluating comfort performances of product/process and to insert those evaluations in product/process development cycle. Also experimental devices are needed for improving methods and for making numerical/experimental correlations. The accuracy and the easiness are the most important characteristics that those methods/devices may have; the integration of those evaluation methods in a DHM software for ergonomic/comfort application can strongly enhance the product/process prototyping in CAD/CAE environment and can give to designers a powerful instruments to preventively evaluate the comfort level of a HMI.

Future developments of this research can be found in the following three lines of research:

For Postural Comfort evaluation, researchers have to develop methods that can take into account:

- Significance of rest posture and of human joints' neutral position;

- Gravitational effect;

- Arms support (like headrest, armrest or other rest surfaces);

- Postural equilibrium (weight distribution and operative spatial conditions);

- Handhold type;

- Repetitive actions' frequency;

- Posture-keeping time;

- Muscular fatigue.

It's also needed a cheap and easy method to measures human joints' angles both in static then in dynamic postures.

For Cognitive Comfort Evaluation, it is necessary to improve:

- Devices to evaluate HMI tactile interaction without altering it during measurement operation; 
Citation: Naddeo A (2013) Virtual Comfort Evaluation as a New Paradigm of Health and Safety In Industrial Engineering. Ind Eng Manage 2: e119. doi: $10.4172 / 2169-0316.1000 \mathrm{e} 119$

Page 3 of 3

- Devices/methods to evaluate HMI visual interaction during operation-time

- Methods for allowing users/workers to describe and analyze their own sensations during operation/use time without affecting their perception.

- A method to integrate the other three senses in the evaluation (hearing, taste and olfaction). about:

For Physiologic Comfort evaluation more studies are required

- Devices to measure HMI temperature without altering it during measurement operation;

- Devices to measure HMI pressure without altering it during measurement operation;

- Devices to measure HMI transpiration (water-vapour migration) without altering it during measurement operation; other;

A method to correlate the previously described parameters each

- A method to correlate parameters values and their combination to an accepted level of comfort;

- A method for taking into account physiologic condition vs. elapsed time (prolonged postures).

\section{References}

1. Moes NCCM (2005) Analysis of sitting discomfort: a review. Contemporary Ergonomics 2005. Taylor \& Francis, London 200-204.

2. Vink P, Hallbeck S (2012) Editorial: Comfort and discomfort studies demonstrate the need for a new model, Appl Ergon 43: 271-276.

3. Annarumma M, Pappalardo M, Naddeo A (2008) Methodology development of human task simulation as PLM solution related to OCRA ergonomic analysis. IFIP Int Federation Inf Process 277: 19-29.

4. Naddeo A, D'Oria C, Cappetti N, Pappalardo M (2010) Postural analysis in HMI design: an extension of OCRA standard to evaluate discomfort level. J Achievements Mater Manuf Eng 39: 60-70.

5. McAtamney L, Corlet EN (1993) RULA: a survey method for the investigation of work-related upper limb disorders. Appl Ergon 24: 91-99.

6. Hignett S, McAtamney L (2000) Rapid Entire Body Assessment (REBA). Appl Ergon 31: 201-205.

7. Kee D, Karwowski W (2001) LUBA: an assessment technique for postural loading on the upper body based on joint motion discomfort and maximum holding time. Appl Ergon 32: 357-366.

8. Galinsky TL, Swanson NG, Sauter SL, Hurrell JJ, Schleifer LM (2000) A field study of supplementary rest breaks for data entry operators. Ergonomics 43 : $622-638$

9. Hamberg-van Reenen HH, Van der Beek AJ, Blatter BM, Van der Grinten MP, Van Mechelen W, et al. (2008) Does musculoskeletal discomfort at work predict future musculoskeletal pain? Ergonomics 51: 637-648.

10. Naddeo A, Memoli S (2009) Postural comfort inside a car: Development of an innovative model to evaluate the discomfort level. SAE Int J Passenger CarsMech Sys 2: 1065-1070.

11. Helander MG, Zhang L (1997) Field studies of comfort and discomfort in sitting. Ergonomics 40: 895-915.

12. De Looze, MP, Kuijt-Evers LFM, Van Dien JH (2003) Sitting comfort and discomfort and the relationships with objective measures. Ergonomics 46: 985-997.

13. Kuijt-Evers LFM, Groenesteijn L, De Looze MP, Vink P (2004) Identifying factors of comfort in using hand tools. Applied Ergonomics 35: 453458.
14. De Korte EM, Huysmans MA, De Jong AM, Van de Vene JGM, Ruijsendaal M (2012) Effects of four types of non-obtrusive feedback on computer behaviour, task performance and comfort. Appl Ergon 43: 344-353.

15. Vink P, Bazley C, Kamp I, Blok M (2012) Possibilities to improve the aircraft interior comfort experience. Appl Ergon 43: 354-359.

16. Groenesteijn L, Ellegast RP, Keller K, Krause F, Berger H, et al. (2012) Office task effects on comfort and body dynamics in five dynamic office chairs. Applied ergonomics 43: 320-328.

17. Ellegast RP, Keller K, Groenesteijn L, Krause F, Berger H, et al. (2012) Comparison of four specific dynamic office chairs with a conventional office chair: impact upon muscle activation, physical activity and posture. Appl Ergon 43: 296-307.

18. Franz MM, Durta A, Zenk R, Desmet PMA (2012) Comfort effects of a new car headrest with neck support. Appl Ergon 43: 336-343.

19. Kong YU, Kim DM, Lee KS, Jung MC (2012) Comparison of comfort discomfort, and continuum ratings of force levels and hand regions during gripping exertions. Appl Ergon 43: 283-289.

20. Kamp I (2012) The influence of car seat design on its character experience. Appl Ergon 43: 329-335.

21. Noro K, Naruse T, Lueder R, Nao N, Kozawa M (2012) Application of Zen sitting principles to microscopic surgery seating. Appl Ergon 43: 308-319.

22. Kee D, Lee I (2012) Relationships between subjective and objective measures in assessing postural stresses. Appl Ergon 43: 271-276.

23. Zenk R, Franz M, Bubb H, Vink P (2012) Technical Note: Spine loading in automotive seating. Appl Ergon 43: 290-295.

24. Tilley AR (1993) Henry Dreyfuss Associates, The Measure of Man and Woman: Human Factors in Design.

25. Cappetti N, D'Oria C, Naddeo A (2011) New comfort evaluation criteria application on movie-theatre design. In: Daur Università di Padova. IMProVe 2011-Proceedings.

26. Apostolico A, Cappetti N, D'Oria C, Naddeo A, Sestri M (2013) Postural Comfort Evaluation: Experimental Identification of Range of Rest Posture for human articular joints. Int $\mathrm{J}$ Interact Des Manuf.

27. Cappetti N, D'Oria C, Naddeo A Proposal of a new quantitative method for postural comfort evaluation. Int J Appl Ergon.

28. Naddeo A, Cappetti N, Ippolito O Global comfort rating method for reachability and usability of dashboard commands by automotive drivers. Int J Ergon. 